\title{
Evaluation of Progressive Collapse Resistance of Multi-Storey RC Building by Linear Static Analysis Method
}

\author{
Shaikh Akhibuddin ${ }^{1}$, L.G.Kalurkar ${ }^{2}$ \\ ${ }^{I}(P G$ Student, Department of Civil Engineering, JNEC College, Aurangabad, India) \\ ${ }^{2}$ (Assistant Professor, Department of Civil Engineering, JNEC College, Aurangabad, India)
}

\begin{abstract}
Collapse of building due to gas explosion or due to bombing has been occurred in past. Due to explosion a local load carrying member fails and the load carried by failed member get transferred as extra loads to adjacent members which are generally not designed for that, due to extra loads adjacent members gets failed in such a manner whole building collapses. Due to increase in terrorist activity Progressive collapse resistance buildings are need of present and future. In this work resistance to progressive collapse of 12 storey $R C$ Special Moment resistance frame building having 7 and 5 bays each of $4.5 \mathrm{~m}$ in $X$ and $Y$ direction respectively has been evaluated by Linear Static Analysis method. Each is of $3 \mathrm{~m}$ height and General Service Administration (GSA) guild lines has been followed for analysis procedure. Four Column removal case each at one time has been analyzed and DCR ratio has been calculated and compared with limiting value provided by GSA 2013. DCR values for different column removal cases also has been compared and final conclusion has been made.
\end{abstract}

Keywords: Demand to Capacity ratio, General Service Administration, Linear static analysis, PMM, Progressive Collapse.

\section{INTRODUCTION}

Structural engineering researcher get attracted towards the progressive collapse of building after the collapse of some important buildings like Collapse of 22 story Ronan building East London took place due to gas explosion at 18th floor. Also the Murrah Fedral office building in Oklahoma City was collapsed due to terrorist bomb explosion at ground floor (1995). Collapse of world trade center New York which is known to everybody. After collapse of these structures people commensed working on progressive collapse. General Service Administration (GSA) has given guidelines for design of progressive collapse resistant building.

Research on progressive collapse of steel, flat slab and RC frame type designed by American and Euro code has been done by various researchers. Experimental study on the Dynamic response of RC flat slab in the form of 7 one-third scaled model has been done by J.M. Russel et al.[1]. All observed ultimate failure was the punching shear failure at corner column. Progressive collapse resistance of RC structure of ordinary and special moment resisting frame designed by ACI 318 code has been done by Menglu Li et al [2], they observed that frame designing for higher seismic load does not yield good resistance to progressive collapse. Study of 11 storey earthquake resistance RC building under four independent column removal condition has been done by Meng et al [3]. They carried out static linear, nonlinear static and dynamic analysis in SAP2000, they concluded that according to GSA linear static analysis the building has a low potential for progressive collapse while nonlinear static analysis has given a conservative estimation for collapse resistance. Effect of non-structural RC walls on the progressive collapse potential of a RC frames was investigated by Meng- Hao Tsai et al [4], they modelled nonstructural wall as inverted $\mathrm{T}$ beam. DCR of beams in linear static analysis was reduced due to presence of nonstructural walls. In nonlinear static analysis neglecting panel type walls will overestimate the collapse resistance and by neglecting wing type walls shows least adverse effect on the building.

Progressive collapse performance of RC flat plate structure by quasi-static experimental method has been done by Wie-Jain Yi et al [5].it has been observed that compression and tension membrane action are the alternative load paths of the Flat plate RC structures and the failure mode observed was the punching shear failure. Membrane action of flat plate allow structure to carry more loads than design loads. Behavior of RC flat slab frame building under progressive collapse was studied by Seweryn Kokat et al [6]. Progressive collapse assessment of framed reinforced concrete 10 story building according to UFC guidelines for alternate load path method was carried out by Hamed Salem et al [7], Nonlinear dynamic analysis has been done by using Applied Element method (AEM). A set of design criteria for collapse resistance structure was proposed by by Uwe Starossek et al [8].

In this paper Progressive collapse resistance of a 12 storey RC building has been evaluated by using ETABS software and GSA (2013) guidelines. First the framed building has been analyzed and designed in ETABS by Indian codes IS 456 and detailing of reinforcement has done as per IS 13920. Linear static analysis method and a load combination defined by GSA 2(1.2DL+0.5LL) has been used to evaluate member forces and 
DCR ratio. Column PMM ratio has been considered as DCR ratio for compression member. Shear in beams is not the failure criteria as beams has been detailed with Special confinement reinforcement. After evaluation of DCR ratio values are compared with permissible values given in GSA and final conclusions are made.

\section{PROBLEM STATEMENT}

A RC building having plan dimension $31.5 \times 22.5 \mathrm{~m}$ each bay of $4.5 \mathrm{~m}$ and 12 storey each of height 3 $\mathrm{m}$ has been taken for study. Structural system is special moment resisting frame detailed as per IS 13920. Grade of concrete and steel are M-30 and Fe 415 respectively, live load is $3 \mathrm{kN} / \mathrm{m}^{2}$ and FF load is $1.5 \mathrm{kN} / \mathrm{m}^{2}$. Salb thickness is $175 \mathrm{~mm}$, column and beams sizes are mentioned in Table 1 and 2 .

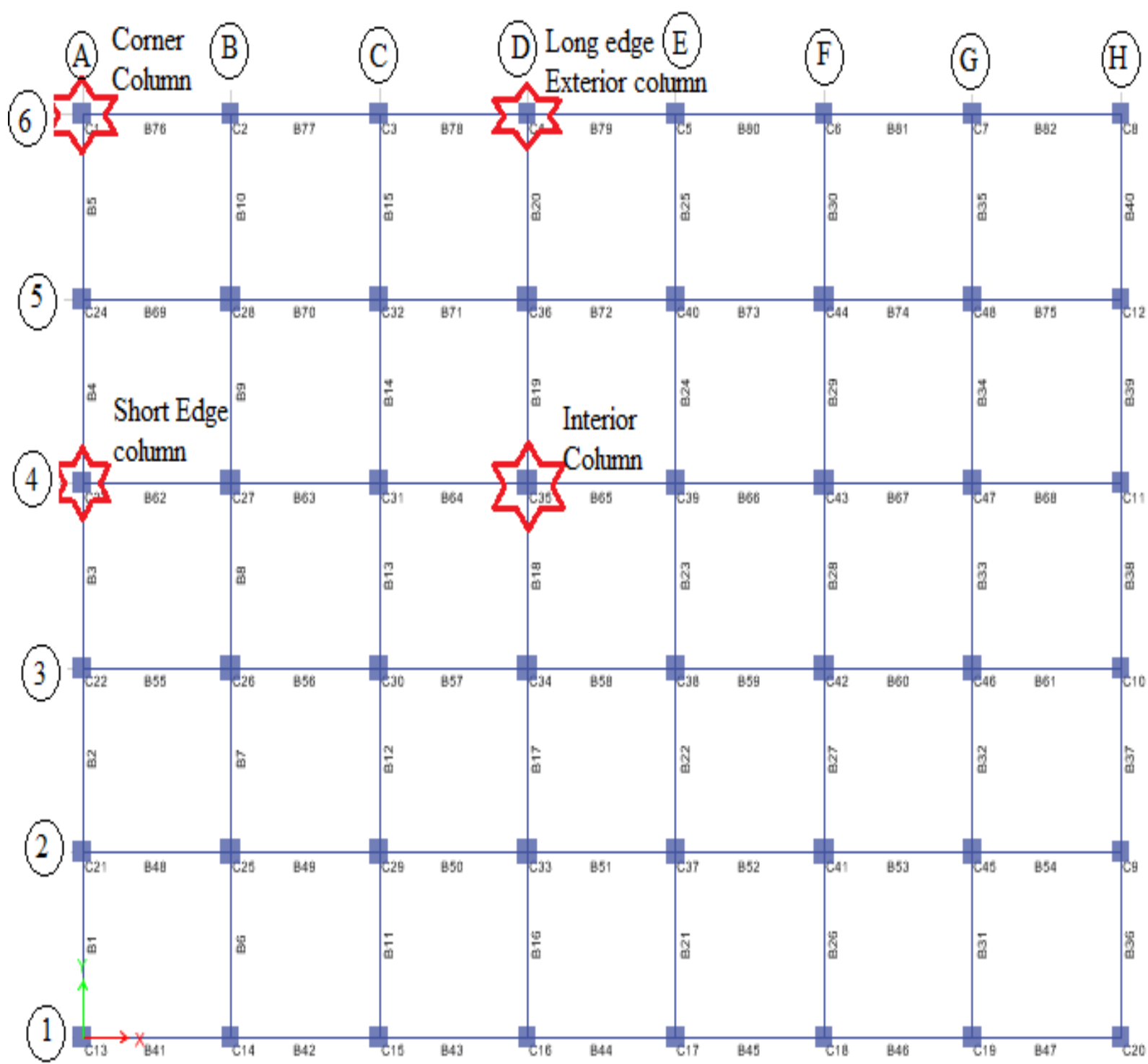

Fig.1 Plan of 12 Storey RC building showing removed column location cases

Table 1 Schedule of columns

\begin{tabular}{|c|c|c|c|c|c|}
\hline Storey & Up to 3rd & 4th to 6th & 7th and 8th & 9th and 10th & 11 th and 12th \\
\hline $\begin{array}{c}\text { Perimeter } \\
\text { columns }\end{array}$ & $700 \times 700$ & $600 \times 600$ & $500 \times 500$ & $450 \times 450$ & $380 \times 380$ \\
\hline \multirow{2}{*}{ Interior column } & $24 \# 20$ & $4 \# 20+14 \# 16$ & $16 \# 16$ & $12 \# 16$ & $8 \# 16$ \\
& $24 \# 20$ & $700 \times 700$ & $600 \times 600$ & $500 \times 500$ & $450 \times 450$ \\
\end{tabular}


Table 2 Schedule of beams $(230 \times 600 \mathrm{~mm})$

\begin{tabular}{|c|c|c|c|c|c|c|}
\hline \multirow[t]{3}{*}{ Storey } & \multicolumn{4}{|c|}{ Reinforcement } & \multicolumn{2}{|c|}{ Stirrups } \\
\hline & \multicolumn{2}{|c|}{ Bottom steel } & \multicolumn{2}{|c|}{ Top steel } & \multirow{2}{*}{$\begin{array}{c}\text { End Region } \\
(\mathrm{mm})\end{array}$} & \multirow{2}{*}{$\begin{array}{c}\begin{array}{c}\text { Mid region- } \\
2 \mathrm{~d}(\mathrm{~mm})\end{array} \\
\text { Dia (Spacing) }\end{array}$} \\
\hline & continue & Curtails & Continue & Extra top & & \\
\hline \multicolumn{7}{|c|}{ Interior long frame beams reinforcement } \\
\hline $11^{\text {th }}$ and $12^{\text {th }}$ & $2 \# 16+1 \# 10$ & - & $2 \# 16+1 \# 10$ & - & $8(75)$ & $8(250)$ \\
\hline $9^{\text {th }}$ and $10^{\text {th }}$ & $2 \# 16+1 \# 10$ & - & $2 \# 16+1 \# 10$ & $1 \# 16$ & $8(75)$ & $8(250)$ \\
\hline $7^{\text {th }}$ and $8^{\text {th }}$ & $2 \# 16+1 \# 12$ & $2 \# 16$ & $2 \# 12+2 \# 10$ & $3 \# 16$ & $8(75)$ & $8(250)$ \\
\hline Below $6^{\text {th }}$ & $3 \# 16$ & - & $2 \# 16+1 \# 10$ & $2 \# 16$ & $8(75)$ & $8(250)$ \\
\hline \multicolumn{7}{|c|}{ Exterior long frame beam reinforcement } \\
\hline $11^{\text {th }} \& 12^{\text {th }}$ & $2 \# 16+1 \# 10$ & - & $2 \# 16+1 \# 10$ & - & $8(75)$ & $8(250)$ \\
\hline $7^{\text {th }}$ and $10^{\text {th }}$ & $2 \# 16+1 \# 12$ & - & $2 \# 16+1 \# 10$ & $1 \# 16+1 \# 12$ & $8(75)$ & $8(250)$ \\
\hline Below $6^{\text {th }}$ & 2\#16+1\#10 & - & $2 \# 16+1 \# 10$ & $1 \# 16+1 \# 12$ & $8(75)$ & $8(250)$ \\
\hline \multicolumn{7}{|c|}{ Exterior short frame beam reinforcement } \\
\hline $10^{\text {th }}$ and $12^{\text {th }}$ & 2\#16+1\#12 & - & $2 \# 16+1 \# 10$ & $1 \# 16+1 \# 12$ & $8(75)$ & $8(250)$ \\
\hline $8^{\text {th }}$ and $9^{\text {th }}$ & 2\#16+1\#10 & $1 \# 12$ & $2 \# 16+1 \# 10$ & $3 \# 16$ & $8(75)$ & $8(250)$ \\
\hline $7^{\text {th }}$ and $6^{\text {th }}$ & $3 \# 16$ & - & $2 \# 16+1 \# 10$ & $3 \# 16$ & $8(75)$ & $8(250)$ \\
\hline Below $5^{\text {th }}$ & $3 \# 16$ & & $2 \# 16+1 \# 12$ & $3 \# 16$ & $8(75)$ & $8(250)$ \\
\hline \multicolumn{7}{|c|}{ Interior short direction frame beam reinforcement } \\
\hline $10^{\text {th }}$ and $12^{\text {th }}$ & $3 \# 16$ & $1 \# 16+1 \# 10$ & $2 \# 16+1 \# 10$ & $3 \# 16$ & $8(75)$ & $8(250)$ \\
\hline $8^{\text {th }}$ and $9^{\text {th }}$ & $3 \# 16$ & $1 \# 16+1 \# 12$ & $3 \# 16$ & $3 \# 16$ & $8(75)$ & $8(250)$ \\
\hline $7^{\text {nd }}$ and $6^{\text {th }}$ & $3 \# 16$ & $1 \# 16+1 \# 10$ & $3 \# 16$ & $3 \# 16+1 \# 12$ & $8(75)$ & $8(250)$ \\
\hline Below $5^{\text {th }}$ & $3 \# 16$ & $1 \# 16$ & $2 \# 16+1 \# 10$ & $3 \# 16+1 \# 12$ & $8(75)$ & $8(250)$ \\
\hline
\end{tabular}

\section{ANALYSIS PROCEDURE OF LINEAR STATIC METHOD}

First modelling and analysis of building in ETABS has been done afterward building has been analyzed with 4 column removal case at ground storey and at $7^{\text {th }}$ storey one at a time as shown in fig 1 . As the beams are provided with confined reinforcement the shear capacity of beam is high and in no column removal case beams are going to fails in shear. Demand to capacity ratio (DCR) of beams for beams in flexure and for columns has been evaluated and compared with limiting value given GSA 2013. DCR ratio has been calculated as ratio of maximum bending moment to capacity of beam at same point and for columns PMM ratio has been considered equivalent to DCR ratio.

\subsection{DCR Ratios of Beams For Flexure}

In following section DCR ratios for critical beams has been evaluated and represented in the form of Bar charts. DCR ratios are evaluated for critical beams for four column removal cases at storey 1 and storey $7^{\text {th }}$. The gravity load along with it earthquake load is also applied on the building under consideration and building's capacity is evaluated by computing its bending moment. Later at different locations i.e Corner, Exterior short edge, Exterior Long edge, Interior columns are removed and their demands are evaluated. Demand to Capacity Ratio can be computed from the above mentioned demand and capacity. After column removal those beams having maximum moment (connected to removed Column) has been considered as critical beams. DCR of beams for flexure has been represented separately for each case of column removal. Taking one critical beam from each column removal case a bar chart has been prepared to compare four cases of column removal at one storey. All obtained DCR ratios for flexure has been compared with limiting values given in General Service Administration (GSA 2013) and progressive collapse resistance of building has been evaluated. 

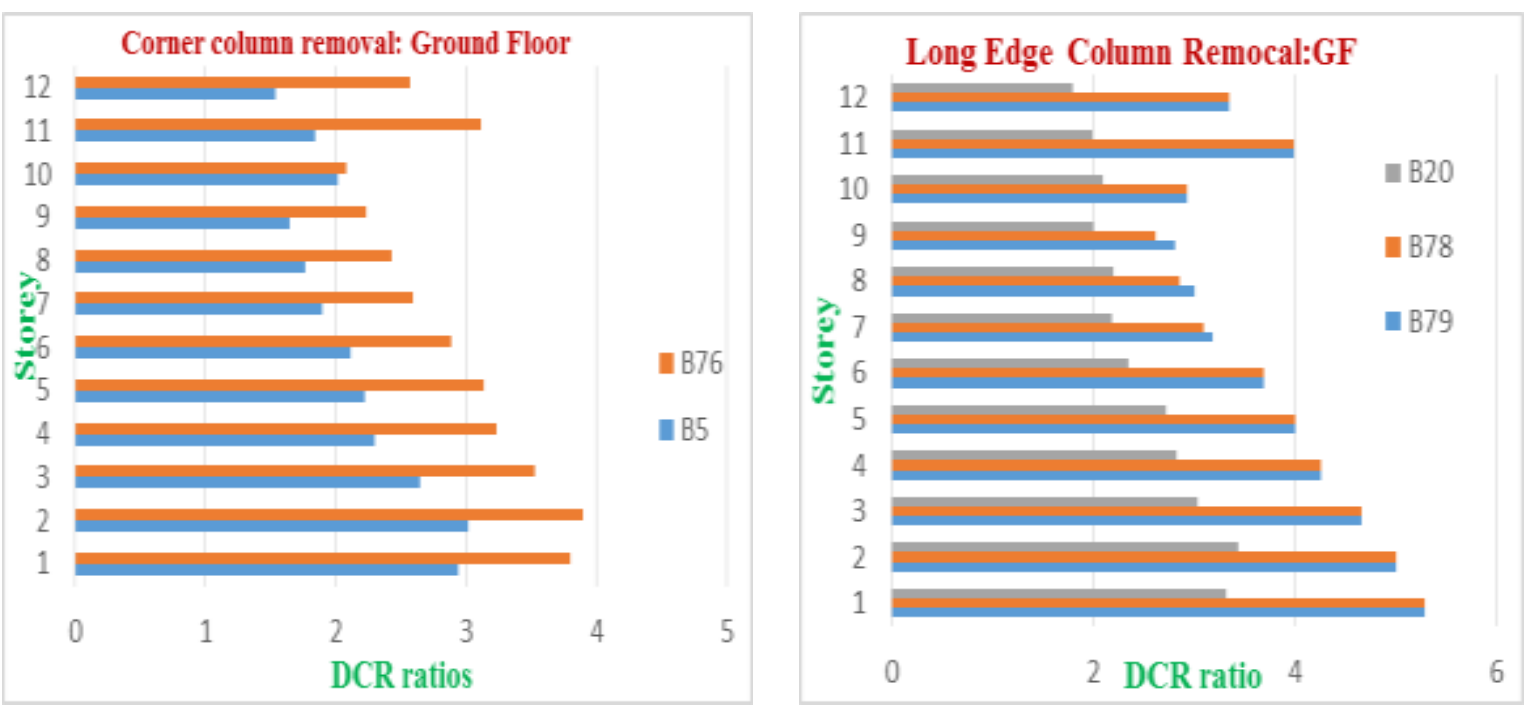

Fig 2 DCR of beams in Flexure for Corner (A-6) and Long Edge (D-6) column removal at GF
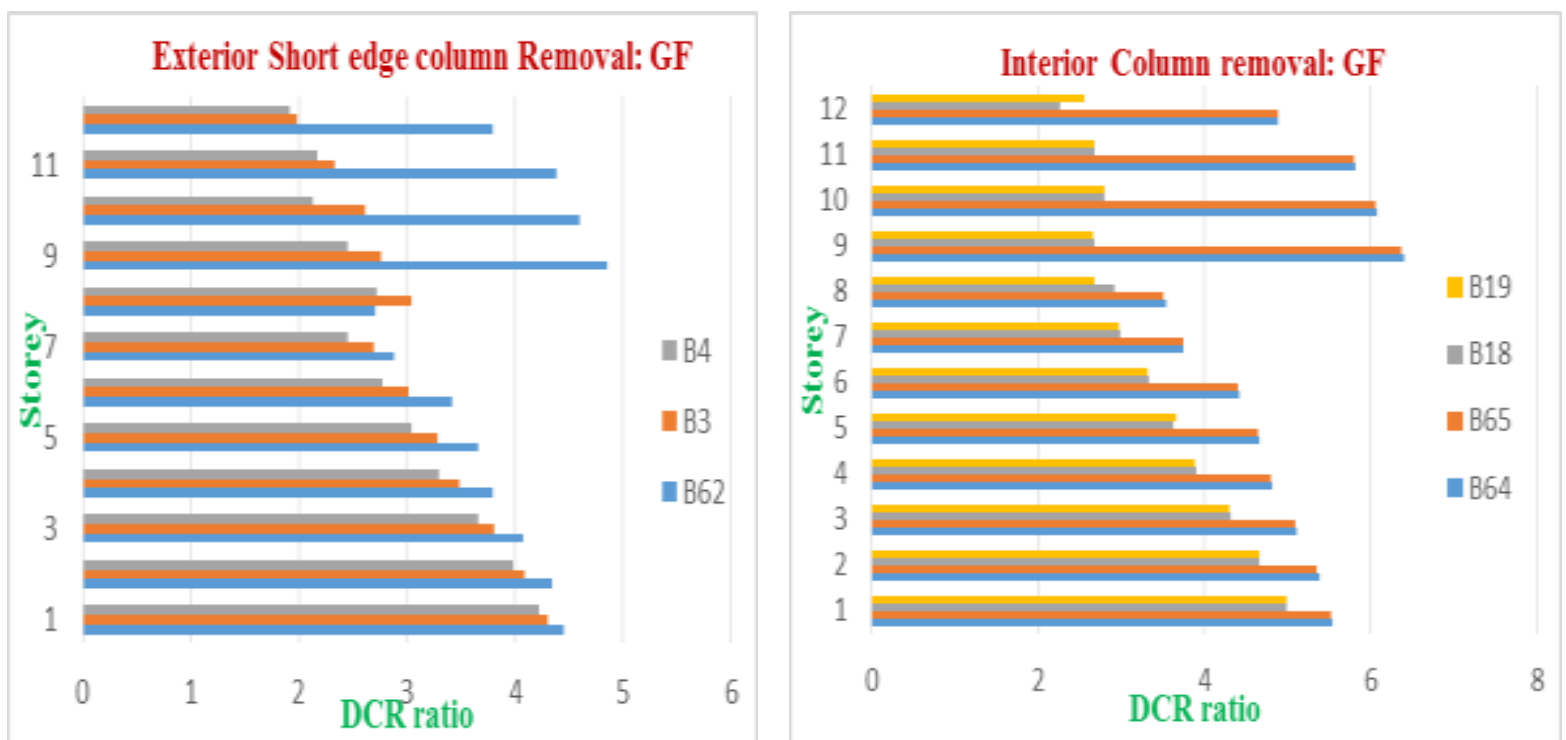

Fig 3 DCR of beams in Flexure for Short Edge (A-4) and Interior(D-4) column removal at GF
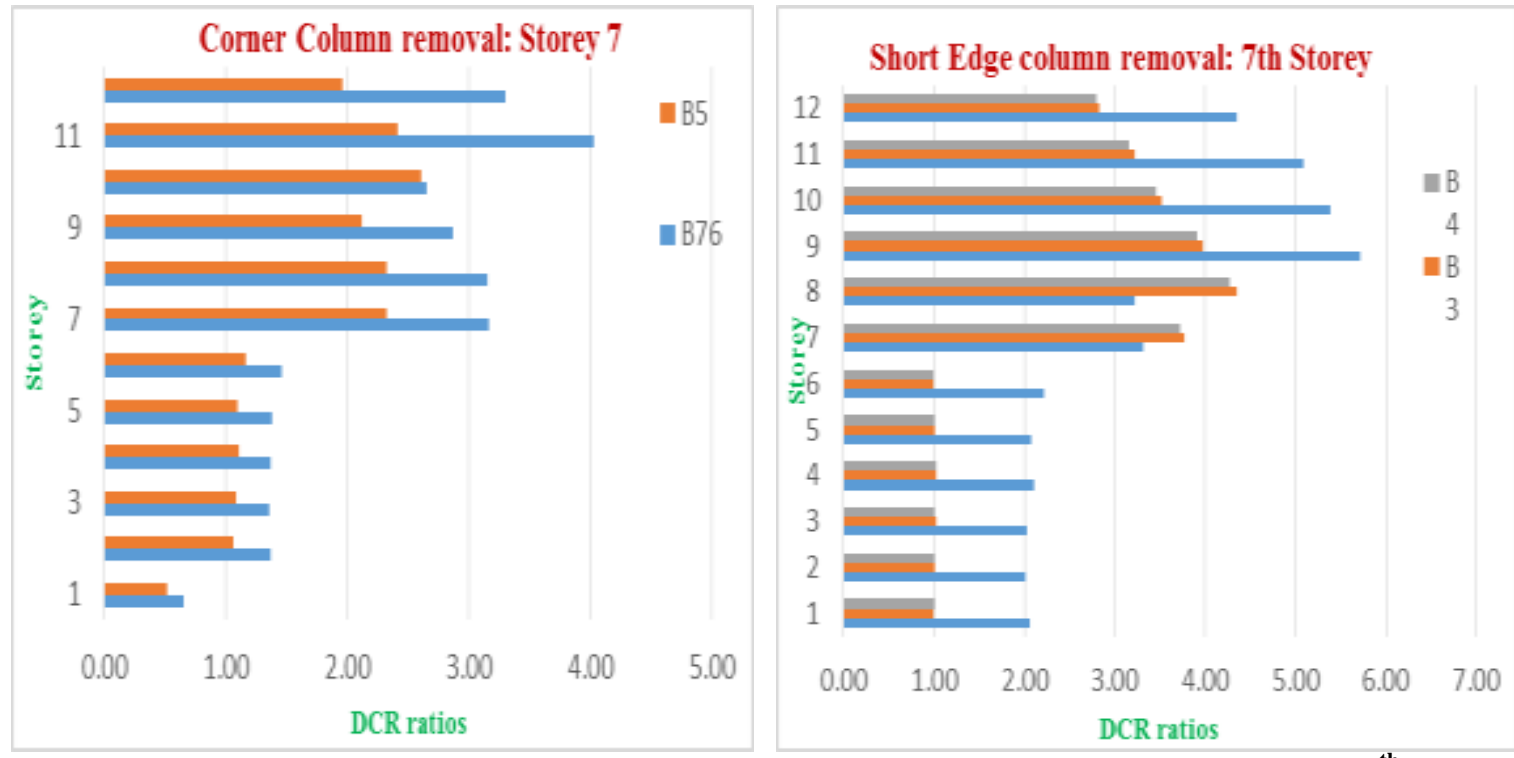

Fig 4 DCR of beams in Flexure for Corner (A-6) and Short Edge (D-6) column removal at $7^{\text {th }}$ Storey 

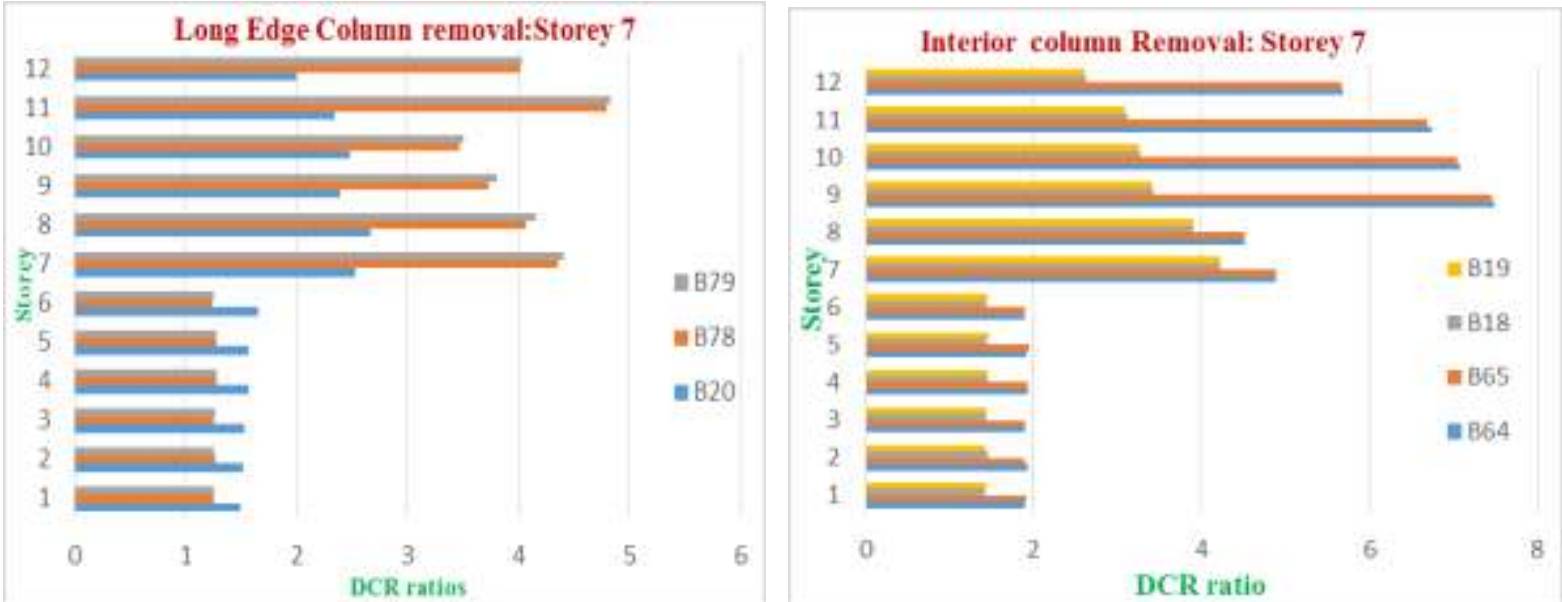

Fig 5 DCR of beams in Flexure for Long Edge(A-4) and Interior(D-4) column removal : $7^{\text {th }}$ floor
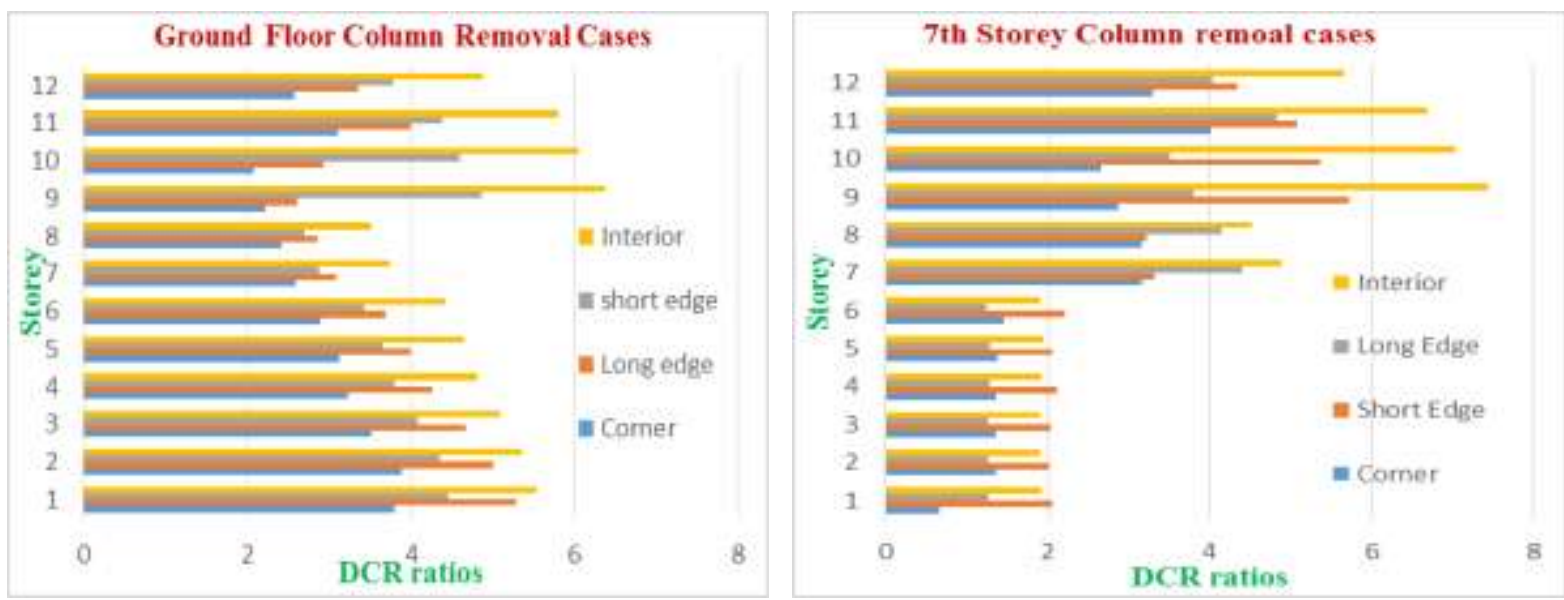

Fig 6 DCR ratio of beams for flexure for all column removal cases at GF and 7th storey

\subsection{DCR Ratios Of Beams For Shear}

DCR ratio of beams for shear has been evaluated for Corner column removal at ground floor. As the frames are detailed as per IS13920, there is confinement of concrete in beams near support and stirrups has been placed close to each other, which leads to high capacity of beam in shear due to which DCR ratio is less for shear. Fig 7 shows CR ratio of two beams in column removal case.

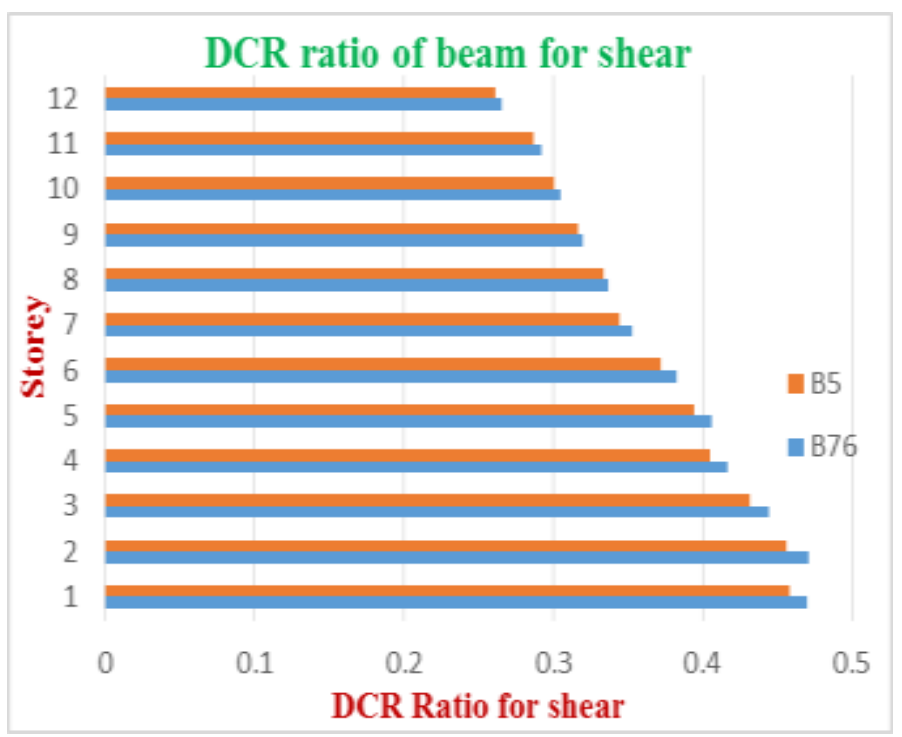

Fig 7 DCR ratio of beams for Shear for corner column removal case 


\subsection{PMM Ratios Of Columns}

PMM ratio of columns has been taken as DCR ratios. PMM ratio of column are directly obtained from ETABS and represented in in the form of bar chart for each column removal case. PMM ratio of only the column which are in vicinity of removed are mention in bar charts, all the remaining columns are not critical.
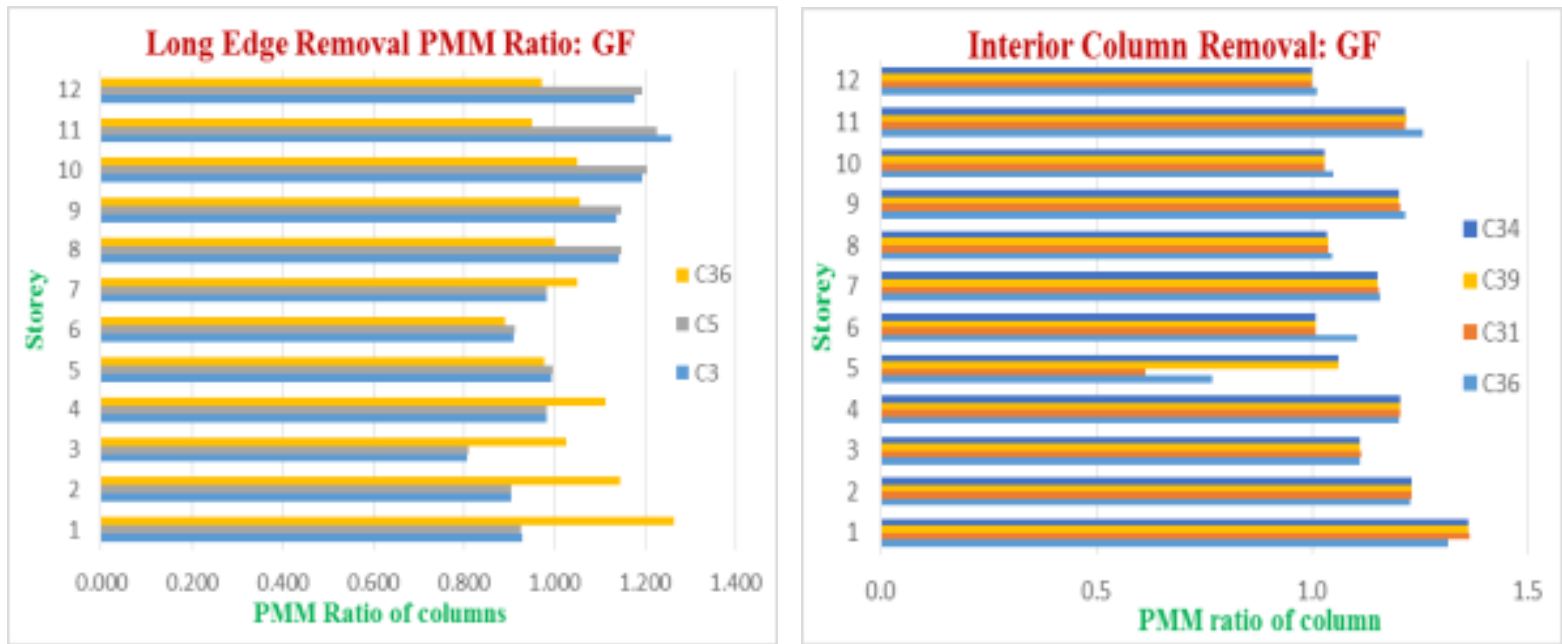

Fig 8 PMM ratio of Long Edge removal (A-4) and interior (D-4) ground column removal
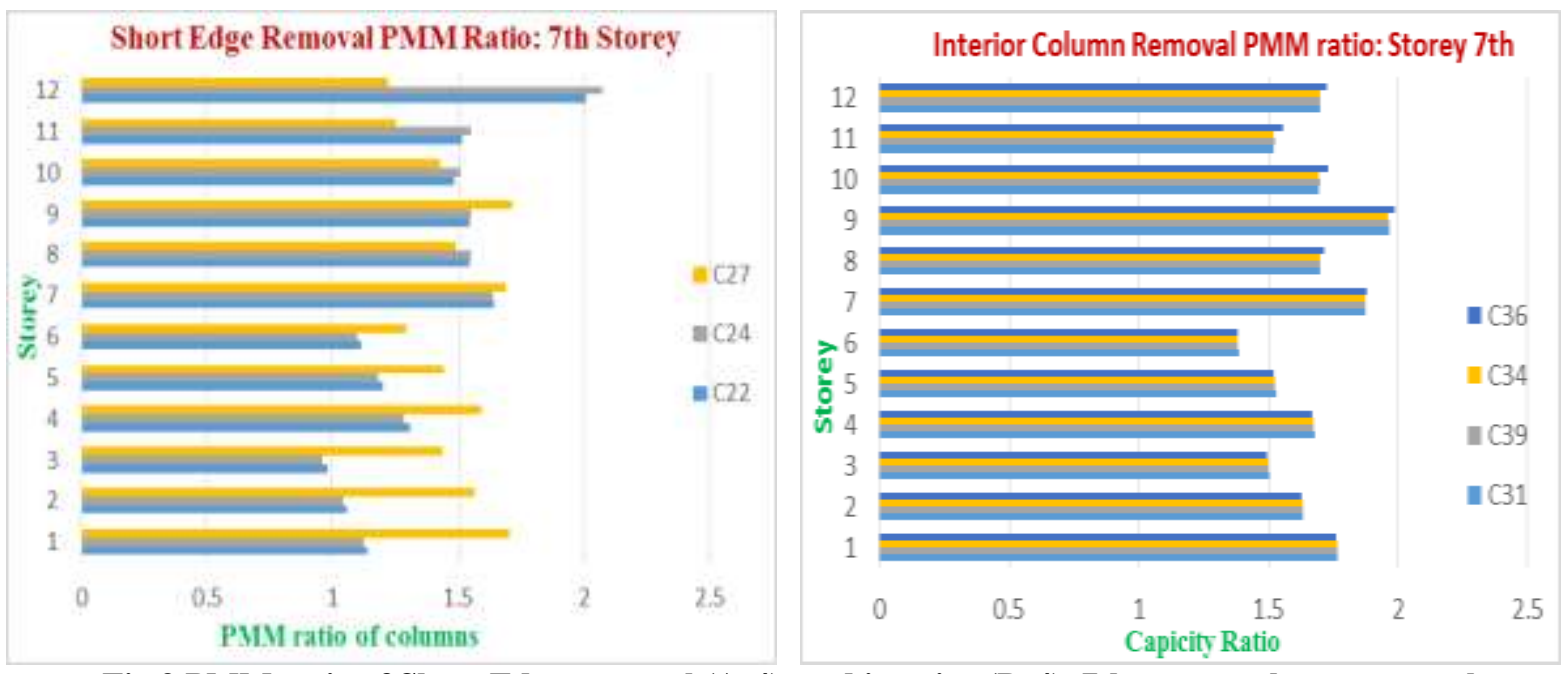

Fig 9 PMM ratio of Short Edge removal (A-4) and interior (D-4) 7th storey column removal
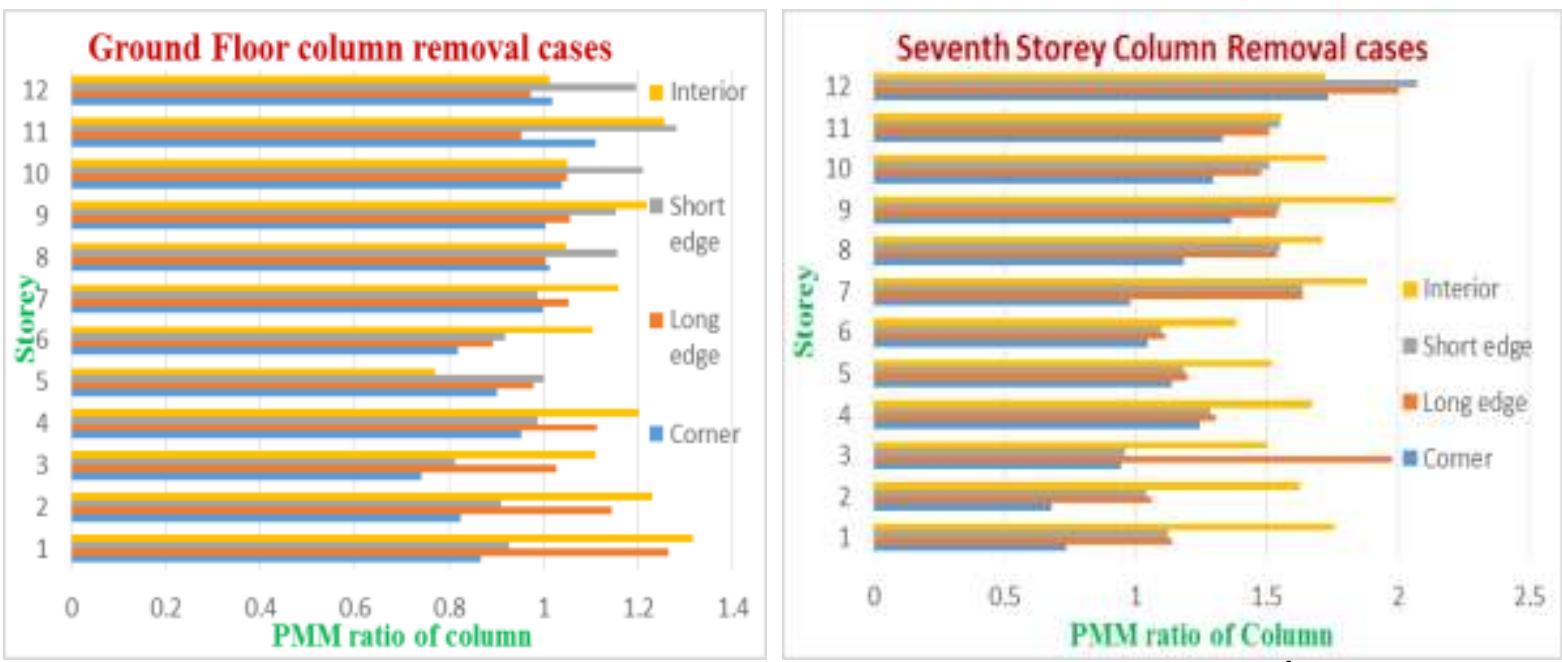

Fig 10 PMM ratio of four cases of column removal at Ground storey and $7^{\text {th }}$ storey 


\section{DISCUSSION ON RESULTS}

DCR ratio for beams in shear and flexure has been calculated and PMM ratio for column has been evaluated from ETABS. As per ASCE 41 [10] for primary member with low ductility member is going to fail when its DCR ratio exceeds 2.0. For ground column removal cases DCR ratios of most of the beams in flexure exceeds 2.0 which means that these beams are going to fail under the loss of respective column. From fig 2 and 3 it has been observed that for Corner column and long edge column removal at ground floor cases lower storey beams are critical and for short edge and interior column removal at ground floor cases upper storey beams are critical. Fig 6 shows that among all four cases of column removal at ground floor interior column removal case is most critical one and corner column removal is least critical. From fig 4, 5 and 6 it is observed that for all column removal cases at $7^{\text {th }}$ storey beams above storey 7 are critical one (failing) and beams below storey 7 are not going to fail, the most critical beams among all cases of $7^{\text {th }}$ storey removal is interior column removal case. DCR ratio for the beams in shear has been shown in fig 7 which indicates that no beam is going to fail in shear for column removal case. Bar chart of column PMM ratio has been shown in fig 8 to 10 which indicated that only one column $(\mathrm{C} 24)$ of $11^{\text {th }}$ storey exceeds acceptance criteria (DCR/PMM $\left.>2\right)$ for short edge column removal at $7^{\text {th }}$ storey and other columns are not critical.

\section{CONCLUSION}

Linear static analysis for progressive collapse resistance evaluation of a 12 storey RC building has been done for four column removal case namely corner, short edge, long edge and interior as per GSA 2013. Column has been removed at ground floor and at $7^{\text {th }}$ storey one at a time and DCR ratios for beams and columns are evaluated and presented in the form of bar charts. By observing the bar charts and values and comparing DCR values of different components of building with acceptance criteria given in GSA 2013 and ASCE 41 [10], following conclusion can be made:

- As the DCR ratio for all the beams in shear is less than 2 no beams in shear are going to fail for any column removal case. Shear in beam is not critical in progressive collapse process of building.

- Since PMM/DCR ratio of most of the column (except C24) is less than 2, columns are not critical in progressive collapse process of building.

- Interior column removal case is the most critical and corner column removal case is least critical for both ground floor column and $7^{\text {th }}$ storey column removal.

- For both the critical cases i.e. ground column interior removal and $7^{\text {th }}$ storey interior removal case upper 4 storey beams (B64) are more stresses than lower storey beams.

- For $7^{\text {th }}$ storey column removal cases beams only beams above $7^{\text {th }}$ storey going to fail and the beams below $7^{\text {th }}$ storey are not going to fail as DCR ratio is less than 2.

- Redesigning of beams in flexure is required to prevent the progressive collapse of building.

\section{REFERENCES}

[1] J.M. Russell, J.S. Owen and I. Hajirasouliha, Experimental investigation on the dynamic response of RC flat slabs after a sudden column loss, Engineering Structures 99, 2015, 28-41.

[1]. Vikram Singh Thakur, Vikas Khatuja,Dr. C.B.K. Rao, Simplified Analysis of Reinforced Concrete Framed Structures for Progressive Collapse, International Journal of Scientific \& Engineering Research 4, 2013, 264-271.

[3] Hao Wang, Anqi Zhang,Yi Li Weiming Yan, A Review of Progressive Collapse on Building Structures, The Open Civil Engineering Journal 8, 2014, 183-192.

[4] Meng-Hao Tsai and Tsuei-Chiang Huang, Progressive Collapse Analysis of an RC Building with Exterior Non-Structural Walls, Procedia Engineering 14, 2011, 377-384.

[5] Rakshith K G, Radhakrishna, Progressive Collapse Analysis of reinforced Concrete Framed Structure, ,International Journal of Research in Engineering \& Technology 9, 2013, 36-40.

[6] Huda Helmy, Hamed Salem and Sherif Mourad, Progressive collapse assessment of framed reinforced concrete structures according to UFC guidelines for alternative path method, Engineering Structures 42, 2012, 127-141.

[7] Uwe Starossek and Maren Wolff, JCSS and IABSE Workshop on Robustness of Structures.

[8] Phillip J. Georgakopolous, An Overview Of Progressive Collapse in Structural Systems, M.E, Massachusetts Institute of Technology (MIT), Syracus University, 2004.

[9] IS 1893 (Part 1): 2002, Criteria for Earthquake Resistant Design Of Structures, Bureau of Indian Standards

[10] IS 456:200, Plain and reinforced code of concrete ( $4^{\text {th }}$ Revision), Bureau of Indian Standards

[11] IS 13920: 1993, Ductile Detailing of Reinforced Concrete Structures Subjected to Seismic Forces, Bureau of Indian Standards. 